\title{
A COMPARATIVE ANALYSIS OF MACHINING PARAMETERS INFLUENCE ON ACCURACY AND ROUGHNESS IN WATERJET AND LASER CUTTING
}

\author{
Marek Placzek ${ }^{1}$, Paulina Fabisz ${ }^{2}$ \\ ${ }^{1}$ Silesian University of Technology, Faculty of Mechanical Engineering, Department of Engineering Processes Automation \\ and Integrated Manufacturing Systems, Konarskiego 18A, 44-100 Gliwice, Poland \\ ${ }^{2}$ Azet-flex, Toruńska 27, 44-100 Gliwice
}

Corresponding author: Marek Płaczek, marek.placzek@polsl.pl

\begin{abstract}
The paper presents a comparative analysis of the technique of cutting materials such as water jet cutting and laser cutting. The tests were carried out while cutting plastic elements, such as: PMMA, HIPS and ABS. To compare the analysed cutting methods, it was necessary to limit the type of material to be cut to the selected plastics due to the limited thickness range of the samples cut with the use of the laser used for the tests. The workpiece was designed in AutoCAD. The geometry was designed in such a way that it was possible to compare the accuracy of cutting both straight sections, curves and holes using the cutting techniques tested. The roughness of the treated surfaces (edges of the samples) was also analysed. A roughness gauge was used to test the edges. The obtained research results were compiled and analysed to determine the optimal technology and parameters of cutting processes for individual types of selected materials and shapes. As it was shown, the wrong selection of the cutting technology in relation to the processed material or the wrong selection of machining parameters may lead to the destruction of the detail being made and incur significant costs.
\end{abstract}

Key words: waterjet cutting, laser cutting, processing parameters, analysis, surface quality, roughness.

\section{INTRODUCTION}

Cutting is, in other words, the process of separating material. The ideal cutting process is one in which the separation of the material (atomic bonds) takes place along a predetermined trajectory without affecting the physical condition of the material. Today there are many methods of cutting various materials. However, these methods differ from each other, e.g. in the amount of energy used during the material separation process, cutting speed, amount of material loss, amount of heat generated during the process, as well as the quality of the cut edges. Choosing the right type of cutting technology can save the company from incurring huge costs. Before choosing a cutting technology, one should familiarize oneself with the possibilities offered by a particular technique and what surface quality can be achieved with each of the material processing options. With large orders, it is also worth focusing on the processing time with the use of various devices. Sometimes, slight variations in time in piece machining can be fundamental to timing in mass production. In many companies, timely execution is as important as the constructor's requirements for surface quality. Many cutting techniques are available today [10]. It should be emphasized, however, that in some cutting techniques it is not possible to cut material above a certain thickness. The type of material being cut is another key issue when selecting the cutting technique $[1,10]$. One of these technologies is the use of waterjet treatment. The advantage of the waterjet machine is the wide range of cutting possibilities of various materials (glass, stone, composites, ceramics, wood, plastics), the ability to cut complex shapes, obtaining high accuracy of shape, high precision of cutting objects and no requirements for the use of additional cooling fluids due to the fact that the cutting temperature does not exceed $40{ }^{\circ} \mathrm{C}$. The technology also has some disadvantages: high cost of the device and the nozzle; high noise level during processing, the penetration of abrasive under the protective foil (e.g. used for plastics, an ill-considered attempt to remove it from under the foil may result in scratching the material surface) and the need to frequently clean the device's tub. The second available cutting technology is laser cutting. Compared to the abrasive jet cutting device, the laser significantly facilitates long hours of work due to the low noise generated during processing. However, when cutting and the accompanying evaporation of the material, an unpleasant odor is produced, which makes long-term work in the vicinity of the machine becomes tedious and may be harmful to health. Materials after laser cutting do not require finishing, and cutting complex shapes is efficient. The range of the thickness of the cut materials is much smaller than in the case of water cutting. 
The aim of this work is to experimentally compare these two cutting technologies and to determine the influence of machining parameters on the quality of the manufactured elements. These issues are extremely important from the point of view of the selection of the processing technology of elements during production, the selection of processing parameters and the design of the production process technology $[3,4,6]$. Proper implementation of these issues allows to achieve high-quality products and reduce the number of scraps in the production process. This translates directly into production costs and the company's competitiveness. It is therefore not surprising that these issues are the subject of research by scientists and practitioners and are widely discussed in the literature on the subject $[2,5,7,9]$. Among others, the work [10] presents research on the comparison of both methods of cutting materials (waterjet cutting and laser cutting), and compares the cutting parameters and surface quality after using two cutting techniques. Analyzing the surface quality of the products after cutting, it was concluded that the surface quality of the samples and the accuracy of geometric dimensions are comparable after cutting using both techniques, while the abrasive jet cutting machine has much greater possibilities to cut various materials. On the other hand, laser cutting is faster and using this technology one can cut five times more details at the same time. In the article [8], abrasive waterjet processing is presented from the perspective of surface quality after cutting. In conclusion, it is concluded that roughness in abrasive cutting is the main problem with this machining method. For example, when cutting material with a thickness of 30 $\mathrm{mm}$, the roughness of the cut surfaces varies with the height, which is very important when cutting elements of greater thickness. After the treatment, no thermally deformed zones were observed (the temperature during the treatment was $\max 40^{\circ} \mathrm{C}$ ). Moreover, as the feed rate decreases, the accuracy increases and the machining time lengthen. The article [11] also concerns the comparison of laser beam cutting and the abrasive waterjet cutting process. The article presents economic analysis and technical analysis of the cutting process. According to the authors, in economic terms, laser cutting is more profitable, because the cost of cutting one meter is about 3.5 times lower than cutting with a water-jet device (taking into account the initial purchase costs of a laser beam cutting device). According to the authors, when cutting with abrasive water jet, the surface quality can be maintained at the same level with $30-40 \%$ less abrasive or 1.8 times higher head feed speed, and when cutting thin sheets it is possible to cut without the use of abrasive. In this paper, authors also present the results of a comparative experimental analysis of abrasive and laser cutting processes.

\section{RESEARCH METHODOLOGY}

The aim of the research was to perform a comparative analysis of the quality of plastic surfaces after treatment with a laser beam and abrasive water jet. The research was carried out using a CORMAK LC1530C laser with a maximum power of $160 \mathrm{~W}$. The laser working table is $2000 \times 3000 \mathrm{~mm}$ and the positioning accuracy is within the range of $+/-0.1$ $\mathrm{mm}$. The device for abrasive water jet cutting has a work table-bath RT3015-1ST-5-09 with dimensions of 3000x2000 mm. The smallest hole that can be cut has an accuracy of $0.7 \mathrm{~mm}$. With each cutting test, the water pressure parameter was unchanged and amounted to 800 bar. The Surtromoc 3+ HB-103 roughness gauge was used to analyze the surface quality after cutting. The cutting was performed on plastics such as: PMMA, HIPS and ABS. For the comparison of the considered cutting methods, it was necessary to use only these three types of plastics due to the limited scope of the processed materials on the laser, which was used for the research. During the tests, an element designed in AutoCAD, in the form of a cover for the ARDUINO housing, was processed (Figure 1). In the drawing of the cover, additional nozzle movements are marked with red lines, which are responsible for the nozzle access to the holes.

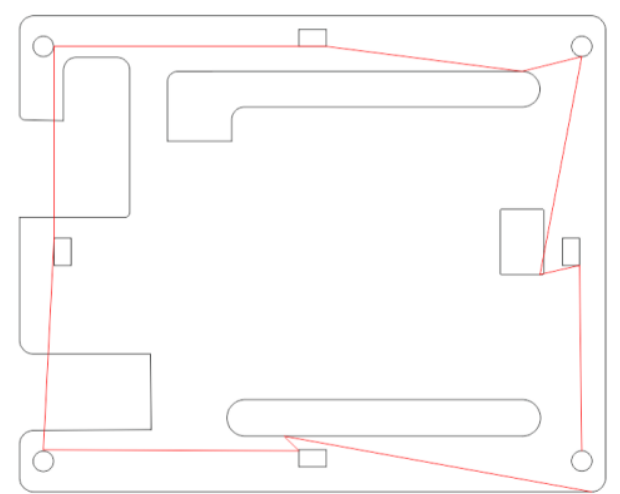

Fig. 1. Drawing of the ARDUINO housing cover in AutoCAD software. Workpiece dimensions 86x70mm

\subsection{Destructive material cutting tests}

In the first stage of the research, destroy tests of cutting of the tested samples were made. This action was aimed at proving that the wrong selection of the cutting technology or processing parameters may cause the destruction of the processed material. The destructive effect of the high-pressure abrasive waterjet was demonstrated. The material that was subjected to the high pressure abrasive cutting test was Dibond. It is a composite panel that consists of several layers of aluminum connected by a polyethylene core. The main parameters used to cut 
the sample were the feed speed of $1500 \mathrm{~mm} / \mathrm{min}$ and the amount of sand $350 \mathrm{~g} / \mathrm{min}$.

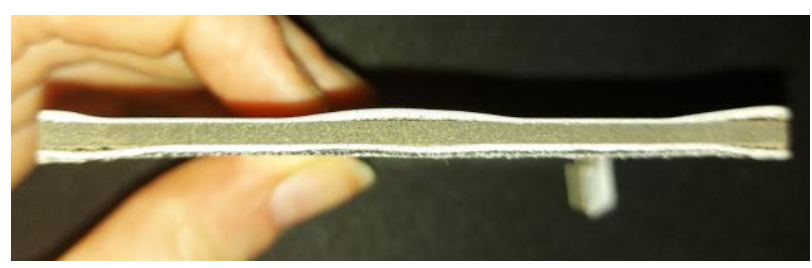

Fig. 2. Cutting $3 \mathrm{~mm}$ dibond at a feed speed of $1500 \mathrm{~mm} / \mathrm{min}$ - effect of the bending of the aluminum layer

In Figure 2, the torn-out aluminum layer is visible, which was torn off under the pressure of the stream from the polyethylene core layer. In addition, the curvature at the cut edge of the material, on which the composite "wave" was created can be seen. The abrasive cutting technique should not be used for cutting Dibond when there is a need to make small parts.

Another material that was damaged during waterjet cutting was three-layer PVC.

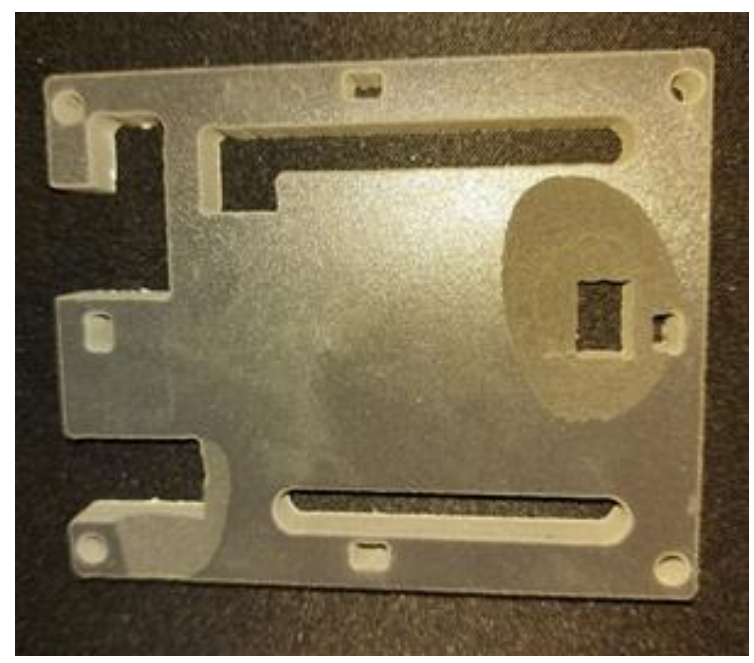

(a)

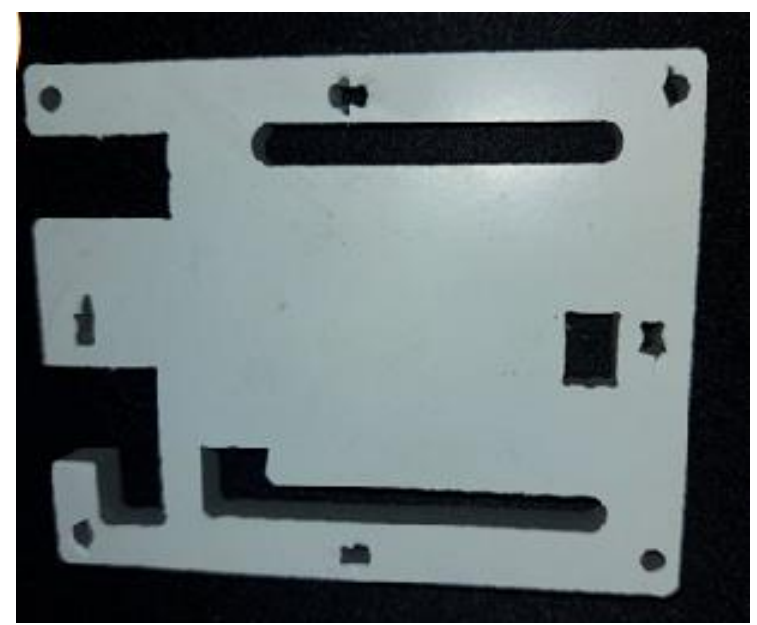

(b)

Fig. 3. Sample after abrasive cutting for three-layer PVC: a) top view, b) bottom view of the sample
Figure 3 shows a sample after waterjet cutting with a feed speed of $3700 \mathrm{~mm} / \mathrm{min}$ and the amount of abrasive $220 \mathrm{~g} / \mathrm{min}$. On the upper part of the sample (a) the part that came in contact with the highpressure abrasive jet first, tears in the material are visible in several places. The lower part of the sample (b) has not properly cut holes where the punctures in the material are also visible. It should be noted that during cutting with high-pressure abrasive waterjet, the materials are chamfered.

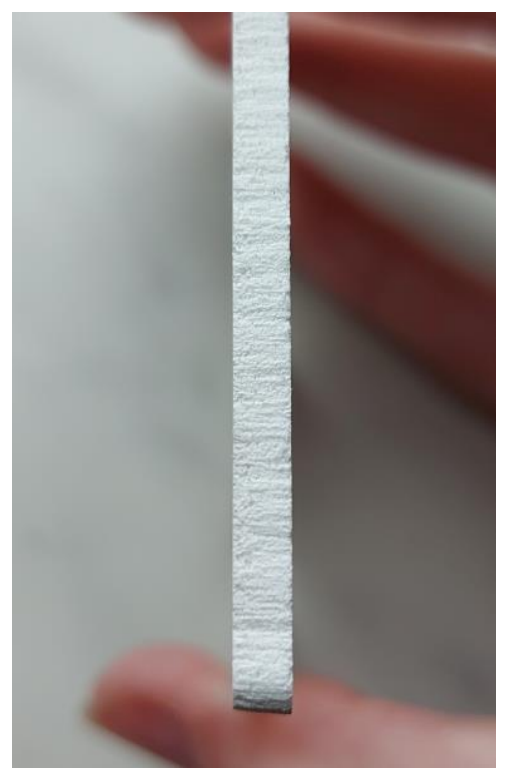

Fig. 4. An example of material beveling on a sample made of $3 \mathrm{~mm}$ thick foamed PVC

The high-pressure abrasive jet has a better cutting accuracy as the jet feed decreases. After cutting the foamed PVC (Figure 4), bevelling of the material was observed due to the selection of too high a parameter of the feed speed.

Another study was to determine the possibility of reducing the cost of cutting with the waterjet technology by eliminating the abrasive. The purchase cost of the "GARNET" abrasive used in the cutting process is significant. This is approximately 400 EIRO per tonne. Before starting cutting tests with the use of waterjet technology in five classes of cut quality, a study of the possibility of cutting all analyzed materials without the use of abrasive was carried out. Cut quality classes mean accordingly:

- Q1 - coarse slitting,

- Q2 - rough cut,

- Q3 - production cutting,

- Q4 - quality cutting,

- Q5 - high quality cutting.

Achieving a given cut quality class depends on the selected processing parameters - mainly on the cutting speed.

In Figure 5, samples made of PMMA with a thickness of $10 \mathrm{~mm}, 8 \mathrm{~mm}, 6 \mathrm{~mm}, 4 \mathrm{~mm}, 2 \mathrm{~mm}$, HIPS $3 \mathrm{~mm}$ and ABS $3 \mathrm{~mm}$ are shown, for which no abrasive 
was not used in the waterjet process. Items are damaged. During cutting, the waterjet hit the thicker samples for the longest time, as shown in the photo. The smaller the thickness of the material, the faster the cutting of the element occurs, the head travel speed increases, which results in less damage.

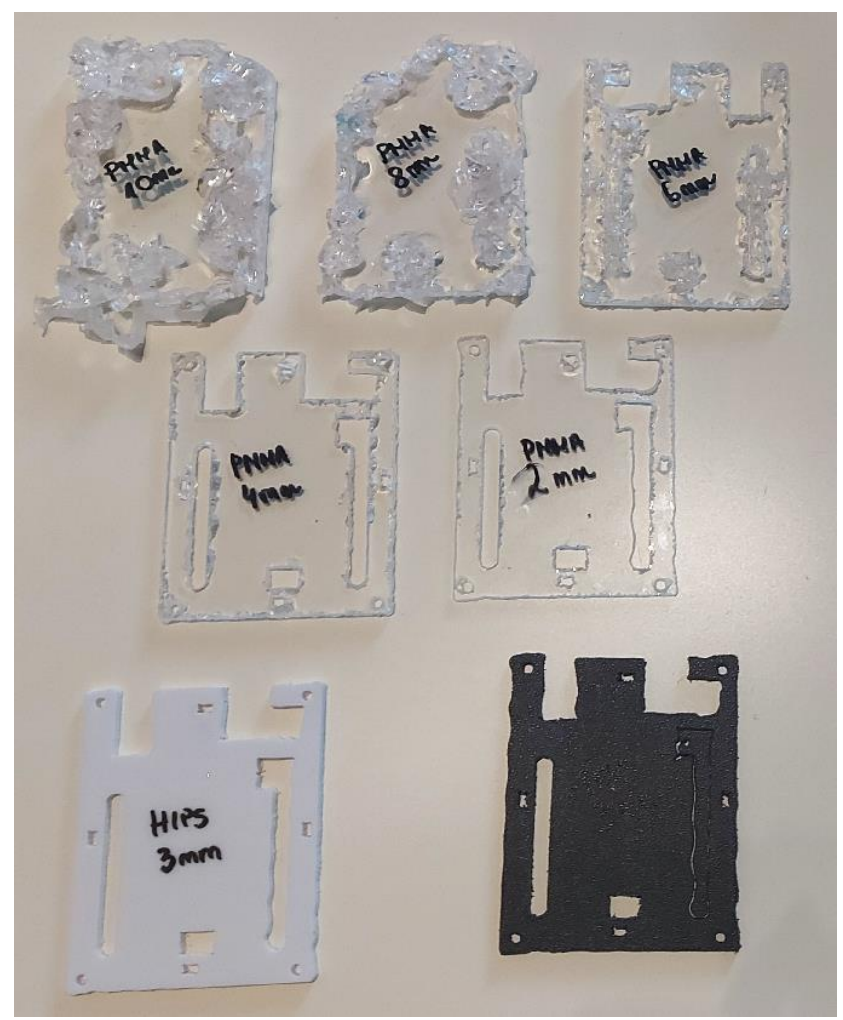

Fig. 5. Samples after cutting on a waterjet plotter without the use of abrasive during the cutting process

PMMA material is not a material that is usually used to cut small parts using the waterjet process because the material near the small holes is destroyed, as shown in Figure 6.

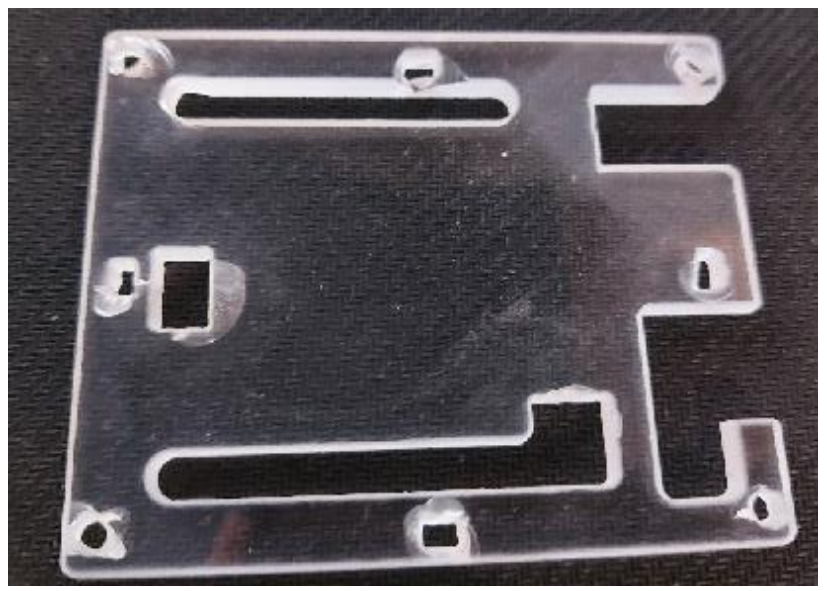

Fig. 6. 4mm PMMA element cutted with a high-pressure water-abrasive jet

The jet hitting the surface of the material causes cracks around the holes and material losses. The lower the cut class, the more visible the defects.
However, the research was carried out to compare the quality of the edges after laser cutting and highpressure abrasive waterjet.

In the case of laser cutting, the main parameters that determine the quality of the cut are the laser power and the cutting speed. The parameters to be set are the laser power in percentage units and the speed in units of $\mathrm{mm} / \mathrm{min}$. In order to show the significant impact of these parameters on the quality of machining, it was checked what is the lowest possible feed of the laser head when cutting materials. After setting the laser power to $99 \%$ and the speed of $0.05 \mathrm{~mm} / \mathrm{min}$, the cutting test was started. The results are presented in Figure 7.

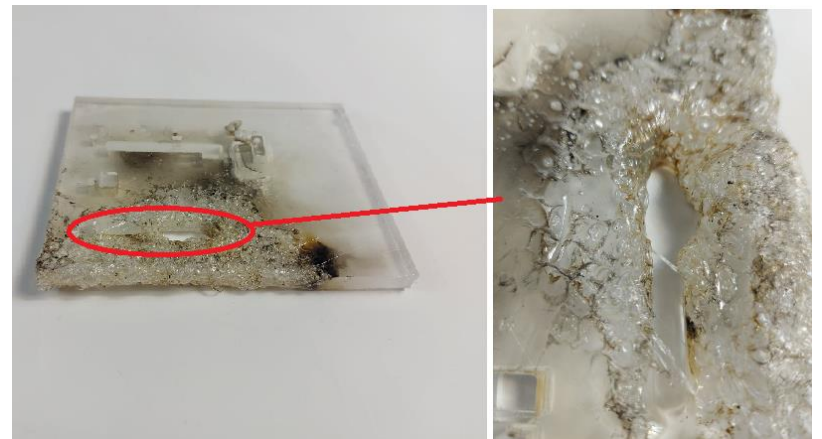

Fig.7. 10mm PMMA sample after laser cutting at a feed speed of $0.05 \mathrm{~mm} / \mathrm{min}$

The material (Figure 7) shows strong melting and smokiness of the protective film on the PMMA. The material started to burn while cutting. In order to avoid this, the successive cuts were carried out with a minimum cutting speed of $0.1 \mathrm{~mm} / \mathrm{min}$.

As shown by destructive tests of the cut samples, the correct selection of the material, cutting technology and technological parameters are of decisive importance for the success of the cutting process and the quality of the manufactured elements. Incorrect selection of these parameters may even lead to the destruction of the material being cut.

\subsection{Research on the influence of cutting parameters on the quality of elements}

For each of the materials used in the tests, the waterjet cutting process was performed six times. Five of them concerned cutting according to classes Q1-5 on the waterjet device, while the class Q0 was symbolically marked as cutting with the minimum use of sand $(1 \mathrm{~g} / \mathrm{min})$, the effects of which are shown in Figure 6. The amount of sand during each test in classes $1-5$ was constant and set according to the manufacturer's recommendations as $380 \mathrm{~g} / \mathrm{min}$. In addition, the water pressure of 800 bar remained the same throughout all the tests, the compensation was set at 0.76 for each cut, and the number of breakthroughs of the abrasive waterjet was 12 (due to the number of holes and one piercing for cutting 
along the material). The cutting speed was a result parameter and adjusted to a given cut quality class.

Two parameters are responsible for the quality and duration of cutting in the case of laser cutting: power and cutting speed. Therefore, a series of tests was performed consisting in cutting the tested materials with a laser using different power and different cutting speed. After all laser cutting attempts have been made, the samples have a relatively smooth edge. Therefore, results of the extreme cutting parameters were collected for the roughness measurement (the highest and the lowest power needed to carry out the cutting process and the highest and the lowest speed).

Compared to cutting with high-pressure abrasive waterjet, laser cutting is characterized by a longer cutting time, which is clearly visible in the case of the thickest sample - PMMA $10 \mathrm{~mm}$. The cutting time with the waterjet method is almost four times shorter when using the parameters for the highest class of cutting. The cutting speed in this technology is directly related to the class of cut. In Figure 9, there is a graph comparing the speed started from the highest grade of cut quality to the lowest one.

\section{ANALYSIS OF THE OBTAINED RESULTS - MEASUREMENTS OF THE ROUGHNESS OF THE CUT SURFACES}

The roughness measurement was carried out using the Surtromoc 3+ HB-103 device. The read values are $R a$ defined as the arithmetic mean of the profile deviations from the mean line, $R z$ defined as the greatest roughness height acc. the top 10 profiles measured and $\mathrm{Sm}$ defined as the mean peaks of the profile on the mean line, measured over the evaluation segment. The parameter taken into account for comparing the two cutting techniques is Ra, from which the average value for both techniques was drawn after three attempts to measure the roughness.

Table 1 summarizes the parameters used during laser cutting of individual samples and the obtained roughness values of the cut surfaces. In the case of laser cutting, the parameter $R a$ presented in the table slightly differs for the highest and the lowest power needed for cutting and the highest and the lowest speed. This shows that the material is subjected to temperature and is melted and partially vaporized. When cutting, a high-quality surface is obtained, and the surface roughness is small.

Table 2 summarizes the parameters of high-pressure abrasive waterjet cutting used for each tested sample. After the waterjet cutting tests were performed, each sample was subjected to roughness measurement. $R a$ differences between each class are visible, and their values are much greater than the results obtained with laser cutting technology. Due to the destruction of the samples as a result of cutting without the use of abrasive, they were not subjected to the roughness measurement. Samples for which the roughness is not specified (no data) were subjected to the roughness measurement test three times, where an error in reading data from the device occurred three times (the value was out of range).

In order to compare the quality of the cut surfaces, in Figure 8 , two samples after cutting with the waterjet method are presented. The sample above was cut in accordance with the parameters for the Q1 class and the sample below in accordance with the parameters for the Q5 class. For the first sample (class Q1), the roughness test shows that the average roughness value $\mathrm{Ra}=32.87 \mu \mathrm{m}$. Damage to the cut surface in the form of loose material is visible. A dull surface occurs in any case when cutting with abrasive water jet, while scratches and indentations going in one direction become more noticeable the worse cutting quality is applied.

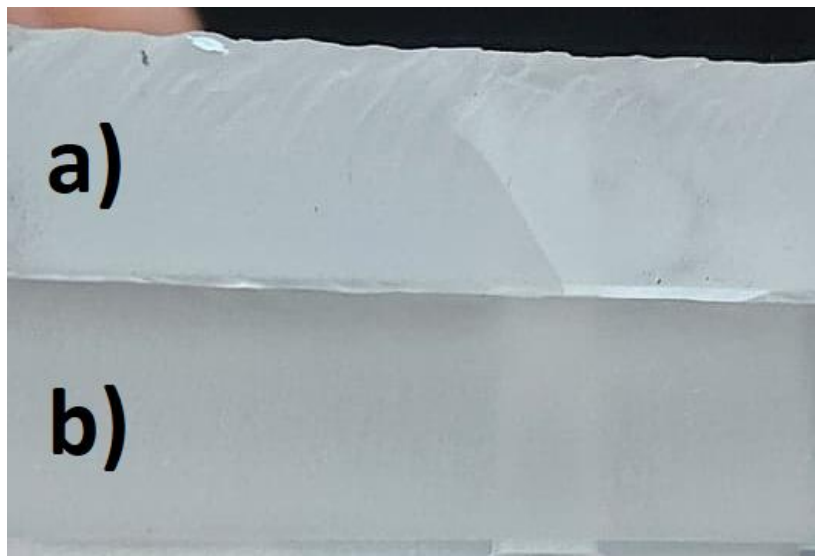

Fig. 8. A list of two 10mm PMMA samples after abrasive waterjet cutting, a) 1st class cutting, $b$ ) 5 th class cutting

Figure 10 shows a bar chart that summarizes the $R a$ parameter of each of the tested samples after laser cutting and the waterjet method. The worst $R a$ parameter is represented by the orange bar. This is the $R a$ parameter obtained during abrasive waterjet cutting for the Q1 class. The graph shows noticeable differences, the roughness values for the cut Q1 class are from the highest for PMMA $10 \mathrm{~mm}$, decreasing for PMMA $8 \mathrm{~mm}, 6 \mathrm{~mm}$ and $4 \mathrm{~mm}$ samples. At PMMA $2 \mathrm{~mm}$, the $R a$ parameter is greater than for PMMA $4 \mathrm{~mm}$. The opposite is true for the Q5 class of abrasive waterjet cutting, while the roughness values of Q1 cut samples decrease, the blue bar corresponding to the Q5 class increases. Another situation is when considering samples after laser cutting. $R a$ roughness differences are almost imperceptible. The gray bar represents the fastest cut using $99 \%$ power for each sample, and the yellow bar represents the slowest cut using the lowest power percentage that can be cut. 


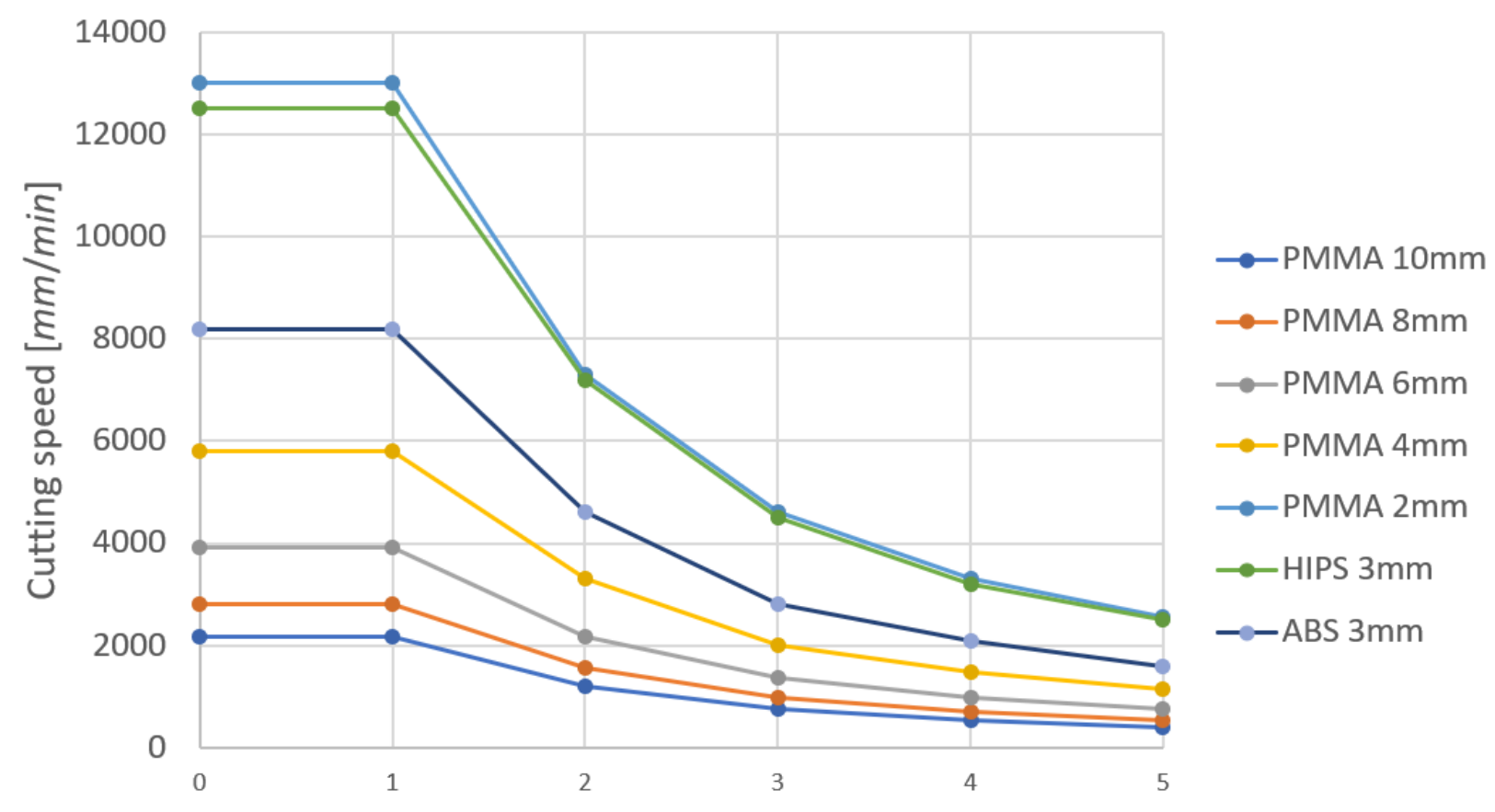

Cutting class

Fig. 9. Changing the cutting speed according to the change of cutting classes

Table 1. Summary of surface roughness measurement results in the case of laser cutting

\begin{tabular}{|c|c|c|c|c|c|c|c|c|c|c|c|c|c|}
\hline & \multirow{2}{*}{$\begin{array}{c}\text { Power } \\
{[\%]}\end{array}$} & \multirow{2}{*}{$\begin{array}{c}\text { Speed } \\
{[\mathrm{m} / \mathrm{min}]}\end{array}$} & \multirow{2}{*}{$\begin{array}{c}\text { Time } \\
\text { [min] }\end{array}$} & \multicolumn{3}{|c|}{ 1st test } & \multicolumn{3}{|c|}{ 2nd test } & \multicolumn{3}{|c|}{ 3rd test } & \multirow[b]{2}{*}{$\begin{array}{l}\text { Average } \\
\text { Ra }[\mu \mathrm{m}]\end{array}$} \\
\hline & & & & $\begin{array}{c}R z \\
{[\mu m]}\end{array}$ & $\begin{array}{c}R a \\
{[\mu m]}\end{array}$ & $\begin{array}{c}S m \\
{[\mu m]}\end{array}$ & $\begin{array}{c}R z \\
{[\mu m]}\end{array}$ & $\begin{array}{c}\boldsymbol{R a} \\
{[\mu \mathrm{m}]}\end{array}$ & $\begin{array}{c}S m \\
{[\mu m]}\end{array}$ & $\begin{array}{c}R z \\
{[\mu m]}\end{array}$ & $\begin{array}{c}\boldsymbol{R a} \\
{[\mu \mathrm{m}]}\end{array}$ & $\begin{array}{c}S m \\
{[\mu m]}\end{array} \mid$ & \\
\hline \multirow{2}{*}{$\begin{array}{l}\text { PMMA } \\
10 \mathrm{~mm}\end{array}$} & 99 & 0.1 & 10.3 & 5 & 1.2 & 1513 & 6 & 1.6 & 2066 & 6 & 1.8 & 3025 & 1.53 \\
\hline & 70 & 0.1 & 10.3 & 4 & 1.2 & 3508 & 4 & 1.2 & 2852 & 3 & 1 & 2727 & 1.13 \\
\hline \multirow{2}{*}{$\begin{array}{l}\text { PMMA } \\
8 \mathrm{~mm}\end{array}$} & 99 & 0.2 & 5.15 & 7 & 1.8 & 1890 & 6 & 1.4 & 2246 & 4 & 0.8 & 1512 & 1.33 \\
\hline & 70 & 0.1 & 10.3 & 3 & 0.8 & 2253 & 3 & 0.8 & 1542 & 4 & 1 & 2460 & 1.53 \\
\hline \multirow{2}{*}{$\begin{array}{l}\text { PMMA } \\
6 \mathrm{~mm}\end{array}$} & 99 & 0.25 & 4.12 & 4 & 0.8 & 1657 & 14 & 3.8 & 2204 & 5 & 1.2 & 1418 & 1.93 \\
\hline & 45 & 0.1 & 10.3 & 3 & 0.8 & 1652 & 5 & 1.2 & 1347 & 3 & 0.6 & 1512 & 0.87 \\
\hline \multirow{2}{*}{$\begin{array}{l}\text { PMMA } \\
4 \mathrm{~mm}\end{array}$} & 99 & 0.5 & 2.06 & 10 & 1.6 & 637 & 16 & 3 & 424 & 16 & 3.2 & 562 & 2.6 \\
\hline & 35 & 0.1 & 10.3 & 24 & 3.6 & 1005 & 30 & 6.4 & 709 & 35 & 6.8 & 742 & 5.6 \\
\hline \multirow{2}{*}{$\begin{array}{l}\text { PMMA } \\
2 \mathrm{~mm}\end{array}$} & 99 & 0.9 & 1.14 & 10 & 1 & 637 & 5 & 1 & 1164 & 6 & 1.4 & 1465 & 1.13 \\
\hline & 99 & 0.1 & 10.3 & 9 & 1.8 & 770 & 10 & 2 & 782 & 16 & 2.4 & 740 & 2.07 \\
\hline \multirow{2}{*}{$\begin{array}{l}\text { HIPS } \\
3 \mathrm{~mm}\end{array}$} & 99 & 0.6 & 1.72 & 10 & 2 & 1024 & 10 & 2.2 & 873 & 8 & 1.8 & 1058 & 1.8 \\
\hline & 70 & 0.4 & 2.58 & 7 & 1.8 & 1518 & 8 & 1.8 & 1420 & 7 & 1.8 & 1238 & 2 \\
\hline \multirow{2}{*}{ ABS $3 \mathrm{~mm}$} & 99 & 0.8 & 1.29 & 18 & 3.4 & 507 & 18 & 2.8 & 365 & 18 & 3.2 & 492 & 2.4 \\
\hline & 50 & 0.4 & 2.58 & 13 & 2 & 395 & 12 & 2 & 340 & 17 & 3.2 & 444 & 2.4 \\
\hline
\end{tabular}


Table 2. Summary of surface roughness measurement results for abrasive waterjet cutting

\begin{tabular}{|c|c|c|c|c|c|c|c|c|c|c|c|c|c|c|c|}
\hline Material & $\left.\begin{array}{c}\text { Th. } \\
{[\mathrm{mm}]}\end{array}\right]$ & $\mathbf{Q}$ & $\begin{array}{c}\begin{array}{c}\text { Amount } \\
\text { of } \\
\text { abrasive } \\
\text { [g/min] }\end{array} \\
\end{array}$ & {$\left[\begin{array}{c}\text { Speed } \\
{[\mathrm{mm} / \mathrm{min}]}\end{array}\right]$} & $\begin{array}{c}\text { Time } \\
{[\text { min }]}\end{array}$ & $\begin{array}{c}R z \\
{[\mu m]}\end{array}$ & $\begin{array}{c}R a \\
{[\mu m]}\end{array}$ & $\begin{array}{c}\mathrm{Sm} \\
{[\mu \mathrm{m}]}\end{array}$ & $\begin{array}{c}R z \\
{[\mu m]}\end{array}$ & $\begin{array}{c}R a \\
{[\mu m]}\end{array}$ & $\begin{array}{c}S m \\
{[\mu m]}\end{array}$ & $\begin{array}{c}R z \\
{[\mu m]}\end{array}$ & $\begin{array}{c}R a \\
{[\mu m]}\end{array}$ & $\begin{array}{c}S m \\
{[\mu m]}\end{array}$ & $\begin{array}{c}\text { Average } \\
\quad R a\end{array}$ \\
\hline \multirow{30}{*}{ PMMA } & \multirow{6}{*}{10} & 5 & \multirow{5}{*}{380} & 400 & 2.6 & 24 & 4.6 & 313 & 31 & 6.2 & 492 & 37 & 6.6 & 329 & 5.80 \\
\hline & & 4 & & 546 & 2.1 & 51 & 8.4 & 197 & 66 & 10 & 220 & 53 & 8.6 & 173 & 9.00 \\
\hline & & 3 & & 760 & 1.72 & 52 & 7.4 & 183 & 65 & 11 & 258 & 57 & 8.2 & 191 & 8.87 \\
\hline & & 2 & & 1212 & 1.33 & 80 & 14.2 & 296 & 100 & 16.8 & 295 & 95 & 18.4 & 329 & 16.47 \\
\hline & & 1 & & 2181 & 1.07 & 131 & 31.6 & 690 & 143 & 32.8 & 821 & 146 & 34.2 & 1015 & 32.87 \\
\hline & & 0 & 0 & 2181 & 1.07 & & & & & & & & & & 0.00 \\
\hline & \multirow{6}{*}{8} & 5 & \multirow{5}{*}{380} & 540 & 2.12 & 51 & 8.2 & 188 & 48 & 7.4 & 238 & 44 & 7.4 & 219 & 7.67 \\
\hline & & 4 & & 706 & 1.78 & 59 & 9.2 & 194 & 46.2 & 7.68 & 162 & 56 & 8.4 & 213 & 8.43 \\
\hline & & 3 & & 982 & 1.48 & 62 & 10.8 & 268 & 57 & 8.6 & 176 & 62 & 10.2 & 207 & 9.87 \\
\hline & & 2 & & 1566 & 1.2 & 103 & 17.6 & 290 & 84 & 15 & 338 & 77 & 13.4 & 285 & 15.33 \\
\hline & & 1 & & 2819 & 0.96 & 117 & 27.6 & 854 & 122 & 25.4 & 764 & 163 & 35.4 & 800 & 29.47 \\
\hline & & 0 & 0 & 2819 & 0.96 & & & & & & & & & & 0.00 \\
\hline & \multirow{6}{*}{6} & 5 & \multirow{5}{*}{380} & 760 & 1.72 & 52 & 7.4 & 159 & 58 & 8.6 & 192 & 64 & 10.8 & 247 & 8.93 \\
\hline & & 4 & & 982 & 1.48 & 60 & 8.6 & 224 & 57 & 9 & 197 & 56 & 9 & 208 & 8.87 \\
\hline & & 3 & & 1368 & 1.27 & 65 & 11 & 258 & 63 & 9.4 & 231 & 66 & 10 & 220 & 10.13 \\
\hline & & 2 & & 2181 & 1.05 & 77 & 14.2 & 369 & 86 & 14.8 & 275 & 102 & 17.6 & 255 & 15.53 \\
\hline & & 1 & & 3925 & 1.05 & 85 & 22.8 & 488 & 80 & 17.8 & 540 & 112 & 19.6 & 382 & 20.07 \\
\hline & & 0 & 0 & 3925 & 1.05 & & & & & & & & & & 0.00 \\
\hline & \multirow{6}{*}{4} & 5 & \multirow{5}{*}{380} & 1150 & 1.6 & 58 & 9.6 & 240 & 56 & 8.8 & 170 & 63 & 9.6 & 206 & 9.33 \\
\hline & & 4 & & 1490 & 1.45 & 42.3 & 7.22 & 123 & 64 & 12 & 274 & 69 & 10.2 & 225 & 9.81 \\
\hline & & 3 & & 2000 & 1.32 & 66 & 11.4 & 274 & 63 & 11.4 & 274 & 64 & 12 & 270 & 11.60 \\
\hline & & 2 & & 3300 & 1.15 & 65 & 11.4 & 223 & 67 & 10.4 & 220 & 66 & 10.8 & 223 & 10.87 \\
\hline & & 1 & & 5800 & 1.05 & 80 & 13.6 & 253 & 72 & 12.4 & 222 & 85 & 14.4 & 237 & 13.47 \\
\hline & & 0 & 0 & 5800 & 1.05 & & & & & & & & & & 0.00 \\
\hline & \multirow{6}{*}{2} & 5 & \multirow{5}{*}{380} & 2560 & 1.5 & 54 & 8.2 & 176 & 63 & 9.4 & 231 & 48 & 8.2 & 180 & 8.60 \\
\hline & & 4 & & 3300 & 1.15 & 112 & 16.8 & 245 & 90 & 16.8 & 26 & 89 & 16.2 & 301 & 16.60 \\
\hline & & 3 & & 4600 & 1 & 94 & 19.4 & 506 & 89 & 14.4 & 263 & 77 & 13 & 246 & 15.60 \\
\hline & & 2 & & 7300 & 0.82 & 108 & 18.6 & 379 & 87 & 14.6 & 258 & 79 & 13.8 & 268 & 15.67 \\
\hline & & 1 & & 13000 & 0.57 & & & & & & & & & & No data \\
\hline & & 0 & 0 & 13000 & 0.57 & & & & & & & & & & 0.00 \\
\hline \multirow{6}{*}{ HIPS } & \multirow{6}{*}{3} & 5 & \multirow{5}{*}{380} & 2500 & 1.27 & 78 & 12.4 & 201 & 77 & 12.2 & 214 & 67 & 11.6 & 173 & 12.07 \\
\hline & & 4 & & 3200 & 1.15 & 86 & 14.2 & 198 & 88 & 14.2 & 248 & 69 & 10.4 & 320 & 12.93 \\
\hline & & 3 & & 4500 & 1.08 & 80 & 12.6 & 191 & 80 & 13.4 & 209 & 85 & 14.6 & 241 & 13.53 \\
\hline & & 2 & & 7200 & 1.02 & 81 & 13.4 & 239 & 67 & 11.4 & 191 & 74 & 13.6 & 230 & 12.80 \\
\hline & & 1 & & 12500 & 0.95 & 80 & 13.4 & 235 & 83 & 13.2 & 219 & 129 & 22.4 & 315 & 16.33 \\
\hline & & 0 & 0 & 12500 & 0.95 & & & & & & & & & & 0.00 \\
\hline \multirow{6}{*}{ ABS } & \multirow{6}{*}{3} & 5 & \multirow{5}{*}{380} & 1600 & 1.42 & 83 & 12.6 & 179 & 74 & 10.2 & 155 & 81 & 12 & 179 & 11.60 \\
\hline & & 4 & & 2100 & 1.3 & 60 & 7.4 & 411 & 115 & 22.2 & 380 & 133 & 20.4 & 291 & 16.67 \\
\hline & & 3 & & 2800 & 1.2 & 116 & 20.6 & 251 & 107 & 20 & 300 & 117 & 19.6 & 266 & 20.07 \\
\hline & & 2 & & 4600 & 1.08 & 94 & 15.2 & 250 & 99 & 17.6 & 261 & 113 & 21.2 & 303 & 18.00 \\
\hline & & 1 & & 8200 & 1 & & & & & & & & & & No data \\
\hline & & 0 & 0 & 8200 & 1 & & & & & & & & & & \\
\hline
\end{tabular}




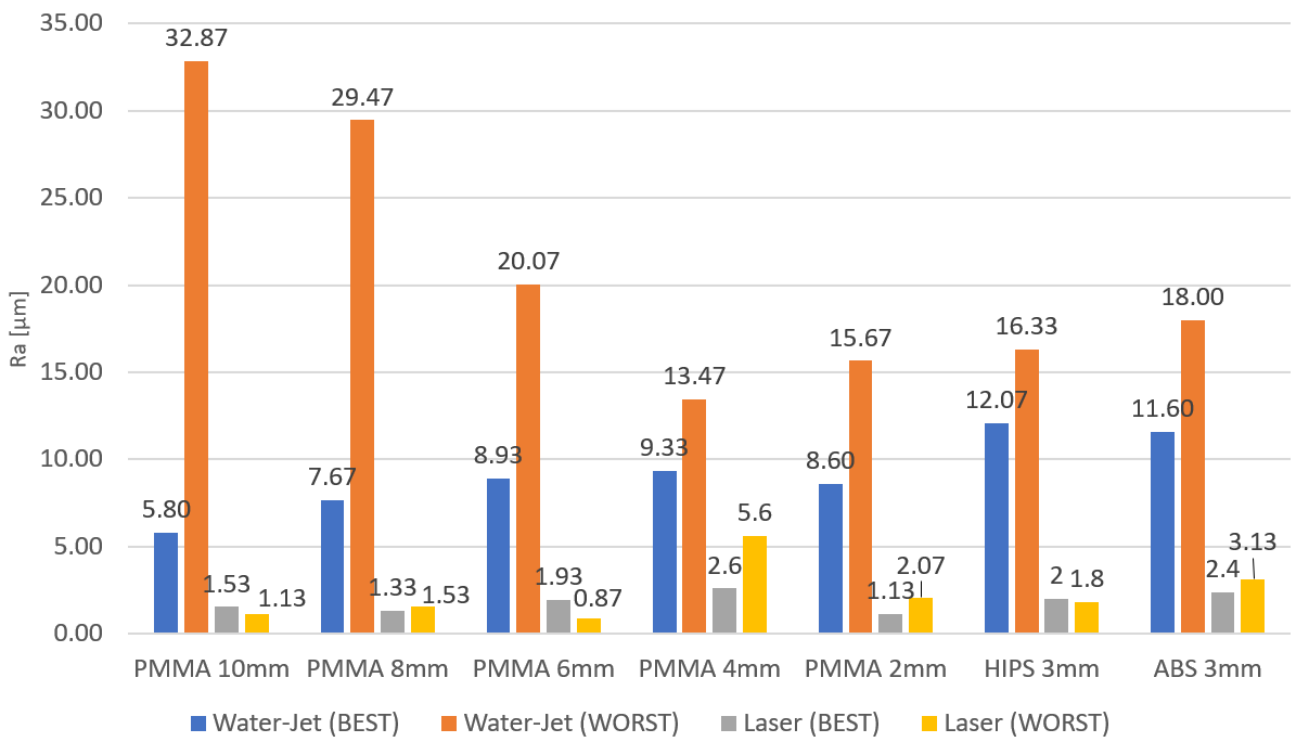

Fig. 10. Comparison of the worst and the best quality material (taking into account the $\mathrm{Ra}[\mu \mathrm{m}]$ parameter) after cutting with both techniques

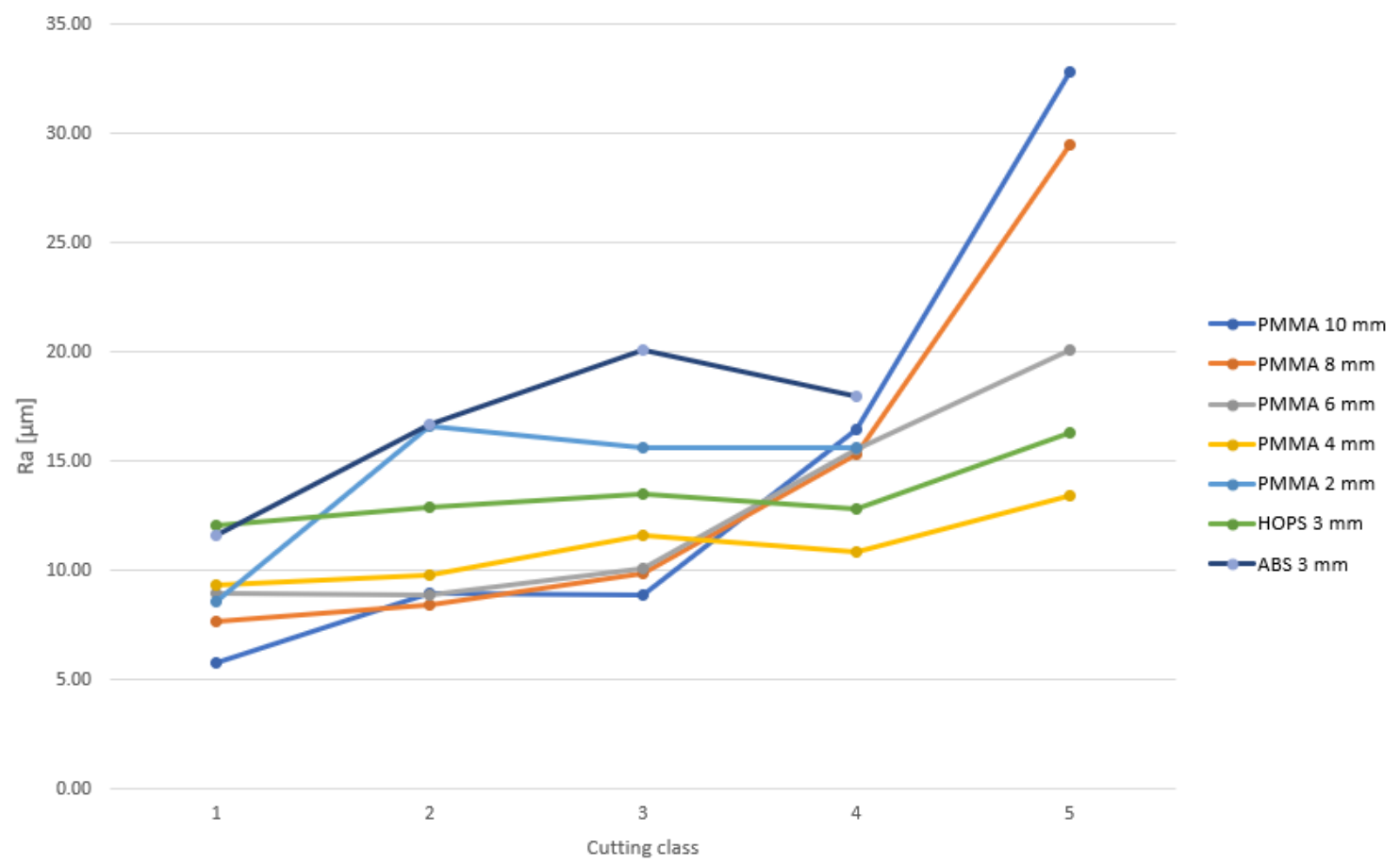

Fig. 5. Comparison of roughness obtained during the waterjet cutting process in relation to a given cutting class

In order to better visualize the results of measuring the roughness of samples after cutting with the waterjet technology, parameter $R a$ has been juxtaposed for each cutting class and each sample in Figure 11. In the case of PMMA $10 \mathrm{~mm}$, the curve on the graph reaches the lowest $R a=5.8 \mu \mathrm{m}$ for the Q5 class and the highest $R a$ value $=32.87 \mu \mathrm{m}$ for $\mathrm{Q} 1$ class. The determined roughness curve has the most linear course in the case of HIPS $3 \mathrm{~mm}$ and PMMA $4 \mathrm{~mm}$ samples. The $2 \mathrm{~mm}$ PMMA and $3 \mathrm{~mm}$ ABS samples were tested three times, but these samples were damaged during cutting and the so-called waves which made it impossible to measure their roughness on the device.

\section{CONCLUSIONS}

Today, various technologies for industrial cutting of materials are available. Each of the available methods has specific advantages and disadvantages. The selection of the appropriate cutting technology and appropriate processing parameters is the basic condition for obtaining the appropriate quality of the manufactured elements, while ensuring optimal energy efficiency of the process. The paper presents the results of a series of laboratory tests on the processing of cut samples with the use of abrasive waterjet and laser cutting technology. The aim of the research was to determine the possibility of cutting various types of plastics with the use of these cutting technologies and to determine the impact of process 
parameters on the quality of the obtained cut surfaces. The conducted tests of various materials cutting technologies with different values of processing parameters and the analysis of the roughness of the samples allow to conclude that cutting with abrasive waterjet is a much faster method of cutting, but the surface is dull and the PMMA material cracks. After laser cutting, the PMMA sample has a smooth surface. The lower the cutting class for the waterjet technology (the lowest class is Q1), the roughness parameter Ra significantly increases, which is visible even when visually assessing the tested samples. Cutting with the waterjet technology without the use of abrasive is almost impossible, because the cut elements are destroyed. Only in the case of thin samples it is possible to obtain a given shape of the cut element. In addition, when cutting with the waterjet method, a chamfer of the cut surfaces is created (see Figure 4). However, in the case of samples cut with the use of a laser, it can be seen that they have a smooth surface and a comparable $\mathrm{Ra}$ roughness parameter, regardless of the power of the laser beam and the cutting speed.

The laser cutting process is a cutting process in which the material melts and evaporates, i.e. interferes with the structure of the material. When cutting with water, the material is cooled by a stream of water, the temperature of the process reaches a maximum of $40{ }^{\circ} \mathrm{C}$, which means no changes in the internal structure or thermal stresses of the processed material. When cutting with waterjet, the area of the processed materials is much larger than when cutting with a laser. Waterjet cutting is definitely more profitable when cutting thicker elements, due to the time aspect of processing, but when cutting thinner materials, laser processing (if it is possible due to the type of material processed) is a better choice due to the quality obtained surface.

As it was shown in point 3.1, the wrong selection of the cutting technology in relation to the processed material or the wrong selection of machining parameters may lead to the destruction of the detail being made and incur significant costs. In the case of waterjet technology, striving to obtain a better quality of the cut surface by using a higher class of cutting is directly related to a significant extension of the processing time, which is associated with its higher costs (see Figure 9). In the case of the tested materials, the use of a lower class of cutting translates directly into obtaining a cutting surface with a higher roughness, and the range of changes in its value is very wide. In the case of a sample made of PMMA with a thickness of $10 \mathrm{~mm}$, the increase in the roughness value was more than five times for the cut quality Q1 compared to the highest cut quality Q5 (see Figure 11). The use of laser cutting results in obtaining a higher quality of the cutting surface, regardless of the selected machining parameters from among their acceptable values in relation to cutting with the abrasive waterjet technology, as well as the changing of machining parameters affect the roughness value in a small extent (see Figure 10).

The research results presented in the study were aimed at a preliminary comparative analysis of the considered plastics cutting technologies and the impact of the selection of processing parameters on the quality of the obtained elements. In the course of further research of the authors, a detailed analysis of the energy consumption of individual cutting technologies will be made and an attempt will be made to determine the machining parameters in individual technologies, optimal in terms of the ratio of the cost of production to the quality of obtained elements.

\section{REFERENCES}

1. Bañon, F., Sambruno, A., et al. (2021) A Review on the Abrasive Water-Jet Machining of Metal-Carbon Fiber Hybrid Materials, Metals, 11, 164.

2. Barabas, S.A., Florescu, A. (2019) Optimization Method of Abrasive Water Jet Cutting of Welded Overlay Materials, Metals, 9, 1046.

3. Choudhury, L.A., Shirley, S. (2010) Laser cutting of polymeric materials: An experimental investigation, Optics \& Laser Technology, 42(3), pp. 503-508.

4. Gvozdev, A.E., Golyshev, I.V. et al. (2015) Multiparametric optimization of laser cutting of steel sheets. Inorg. Mater. Appl. Res., 6, pp. 305-310.

5. Kmec, J., et al. (2020) The Predictive Model of Surface Texture Generated by Abrasive Water Jet for Austenitic Steels, Appl. Sci., 10, 3159.

6. Kulisz, M, Zagórski, I., Koprysa J. (2020) The Effect of Abrasive Waterjet Machnining Parameters on the Condition of Al-Si Alloy, Materials, 13(14), 3122.

7. Kurt, M., Kaynak, Y., Bagci, E. et al. (2009) Dimensional analyses and surface quality of the laser cutting process for engineering plastics, Int. J. Adv. Manuf. Technol., 41, pp. 259-267.

8. Mazurkiewicz, A. (2008) Factors that influence the mistake of the shape and the roughness of the surface after cutting the water-abrasive stream, Inżynieria Materiałowa, 29(6), pp. 686-689 (in Polish)

9. Nguyen, T., Wang, J. (2019) A review on the erosion mechanisms in abrasive waterjet micromachining of brittle materials, Int. J. of Extreme Manuf., 1(1), 012006. 10. Pająk, E. (2016) Waste treatment: technology of machining, abrasive and erosive machining as well as water-abrasive systems on the quality of the cut surface, PWSZ Publishing House, Konin (in Polish) 11. Skoczylas, A. (2000) The comparative analysis of the process of the laser cutting and water jet cutting, Postępy Nauki I Techniki, 8, pp. 121-128 (in Polish).

Received: April 25, 2021 / Accepted: December 20, 2021 / Paper available online: December 25, 2021 (C) International Journal of Modern Manufacturing Technologies 